\title{
Should emotion dysregulation be considered a core component of ADHD?
}

\author{
By Jessica K. Edwards
}

New data from researchers in the USA suggest that emotion dysregulation ${ }^{1}$ should be included as a core component of attention-deficit/hyperactivity disorder (ADHD) rather than viewed as comorbidity. Nigg et al., addressed this long-standing debate by performing a genetic risk analysis in a carefully characterized casecontrol cohort of 514 children aged 7-11 years, defined as children with ADHD or non-ADHD. They computed genome-wide polygenic risk scores for ADHD and depression genetic liability for all participants, and derived well-validated measures of irritability ${ }^{2}$ and emotion dysregulation. They found that emotion dysregulation as a trait was more related to the polygenic risk for ADHD than the polygenic risk for depression. In addition, they found that the relevant emotion dysregulation domain for ADHD genetic risk included irritability, but also extends beyond it to approach-related dysregulation. Their conclusions provide support for a heterogeneity model of ADHD, as originally proposed by Nigg et al. in $2004^{3}$. By this model, ADHD can entail early life breakdowns in regulation of both negative (anger) affect and approach (sensation seeking) motivation, in addition to primary breakdowns in control.

\section{Referring to:}

Nigg, J.T., Karalunas, S.L., Gustafsson, H.C., Bhatt, P., Ryabinin, P., Mooney, M.A., Faraone, S.V., Fair, D.A. \& Wilmot, B. (2019), Evaluating chronic emotional dysregulation and irritability in relation to ADHD and depression genetic risk in children with ADHD. J. Child Psychol. Psychiatr. doi: 10.111/ jcpp.13132.

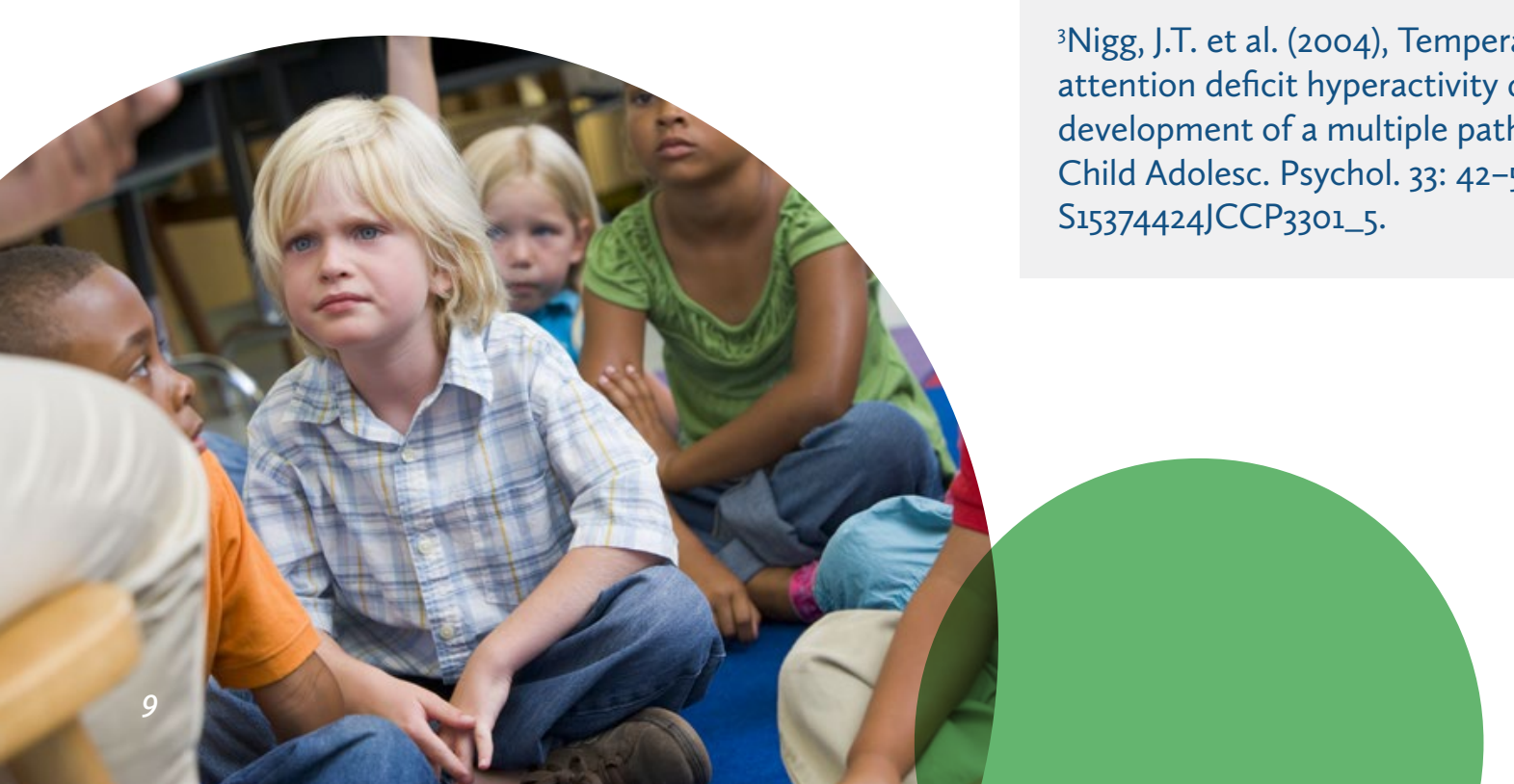

\section{Glossary:}

Emotion dysregulation: van Stralenı defines emotion dysregulation as an inability to modulate emotional responses, resulting in extreme responses of an internalizing or externalizing nature that would be considered inappropriate for the developmental age of the person.

Irritability: Stringaris and Taylor2 define irritability as a proneness to excessive anger, in terms of the frequency, duration, intensity, ease of elicitation and/or uncontrollability.

Polygenic risk score: The cumulative effects of a number of genes that might individually have a small effect on susceptibility; the score is used to predict the likelihood of displaying a particular trait or disease with a genetic component.

Approach-related dysregulation: Approach indicates the propensity to move toward a desired stimulus. Perturbed approach regulation might manifest as sensation seeking or surgency sensation seeking, which in some situations can entail taking physical and/or social risks for the sake of the experience.

\section{References:}

${ }^{1}$ van Stralen, J. (2016), Emotional dysregulation in children with attention-deficit/hyperactivity disorder. Atten. Defic. Hyperact. Disord. 8:175-187. doi: 10.1007/s12402-016-0199-0.

${ }^{2}$ Stringaris, A. \& Taylor, E. Oxford University Press; New York: 2015. Disruptive Mood. Irritability in Children and Adolescents.

${ }^{3}$ Nigg, J.T. et al. (2004), Temperament and attention deficit hyperactivity disorder: The development of a multiple pathway model. J. Clin. Child Adolesc. Psychol. 33: 42-53. doi: 10.1207/ S15374424JCCP3301_5. 